\title{
Microencapsulation of Verapamil Hydrochloride: A Novel Approach for Gastric Retention Using Different Polymers
}

\author{
Patel Manish P*, Patel Jayvadan K, Patel Ravi R and Patel Kalpesh N
}

Department of Pharmaceutics \& Pharmaceutical Technology, USA

\begin{abstract}
The aim of the present investigation was to prepare and evaluate gastroretentive floating microspheres of Verapamil hydrochloride that would retain the drug in stomach and continuously release the drug in controlled manner up to a predetermined time. Floating microspheres were prepared by emulsion solvent evaporation technique. In the present investigation three polymers were used in various concentrations; Methocel K4M, Methocel K15M and Methocel K100M. In vitro performance was evaluated by the usual pharmacopoeial and other tests such as particle size analysis, drug entrapment efficiency, flow properties, in vitro floatability studies, in vivo floatability studies in dog, in vitro drug release studies, stability studies etc. Results showed that the mixing ratio of components in the organic phase affected the size, size distribution, yield, drug content, floating time and drug release of microspheres. In most cases good in vitro floating behavior was observed and a broad variety of drug release pattern could be achieved by variation of the drug, polymer and solvent ratio.
\end{abstract}

Keywords: Floating microspheres; Verapamil hydrochloride; In vitro release

\section{Introduction}

The high cost involved in the development of a new drug molecule has diverted the pharmaceutical industries to investigate various strategies in the development of new drug delivery systems [1]. Drug release from the delivery devices can be sustained up to $24 \mathrm{~h}$ for many drugs using current release technologies. However, the real issue in the development of oral controlled release dosage forms is to prolong the residence time of the dosage form in the stomach or upper gastrointestinal tract until the drug is completely released [2]. The transit of drug or formulation through gastrointestinal tract will determine how long a compound will be in contact with its preferred absorptive site [3]. Prolonged gastric retention improves bioavailability, reduces drug waste and improves solubility for drugs that are less soluble in a high $\mathrm{pH}$ environment. It has also applicable for local drug delivery to the stomach and proximal small intestine [4]. Several approaches are currently used to retain the dosage form in the stomach. These include bioadhesive systems [5], swelling and expanding systems [6,7], floating systems $[8,9]$, and other delayed gastric emptying devices $[10,11]$. The principle of floating preparation offers a simple and practical approach to achieve increased gastric residence time for the dosage form and sustained drug release. Verapamil hydrochloride belongs to the group of calcium channel antagonists, used in the treatment of several cardiovascular disorders, particularly angina pectoris, supraventricular tachycardia and hypertension. In medical practice it is mostly used in a conventional tablet form a minimal dose of $40 \mathrm{mg}$ and a maximal dose of $180 \mathrm{mg}$, and in a slow release form in doses of 120 to $240 \mathrm{mg}$. Only $10-20 \%$ out of the $90 \%$ of the dose absorbed from the digestive tract penetrates to the circulatory system in an unchanged form [12]. The remaining part of Verapamil hydrochloride dose undergoes a first pass effect, mainly in the liver [13]. However, due to its extensive first pass effect it has much low bioavailability (10-20\%). It has shorter half-life $(4 \mathrm{~h})$ hence dosing frequency is high. The physico-chemical properties of Verapamil and is shorter half-life make its suitable molecule for preparation of floating microspheres. The objective of the present study is to develop suitable gastroretentive floating microspheres of Verapamil HCL and to study release kinetics of drug with a view to reduce the dose frequency and to achieve a controlled drug release with improved bioavailability.

\section{Materials and Methods}

\section{Materials}

Verapamil hydrochloride was obtained as a gift sample from Intas Pharmaceutical Ltd., Ahmedabad, India. Methocel K4M, Methocel K15M, and Methocel K100M were received as gift samples from Colorcon Asia Pvt. Ltd., Goa, India. All other ingredients were procured from local market and of analytical grade.

\section{Methods}

Preparation of verapamil hydrochloride floating microspheres: Floating microspheres loaded with Verapamil hydrochloride were prepared by Emulsion solvent evaporation method [14,15]. Overall nine formulations were formulated using different polymers Methocel K4M, Methocel K15M, Methocel K100M as shown in Table 1. Drug and polymer in different proportions 1:1, 1:2, (drug: polymer) were dissolved in 1:1 mixture of solvent system (dichloromethane and ethanol) or (ethyl acetate and acetone). This clear solution was poured slowly as a thin stream in aqueous phase; about $100 \mathrm{ml}$ of polyvinyl alcohol solution with continuous stirring at a speed of $500 \mathrm{rpm}$ using remi stirrer at room temperature until complete evaporation of solvent took place. The floating microspheres were collected by decantation, while the non floating microspheres were discarded along with any polymer precipitates. The microspheres were then dried overnight at $40^{\circ} \mathrm{C}$. The microspheres were weighed and stored in a desiccator until further analysis. Aqueous media (continuous phase) was replaced by liquid paraffin to improve drug loading.

${ }^{*}$ Corresponding author: Patel Manish P, Associate professor, Department of Pharmaceutics \& Pharmaceutical Technology, USA, E-mail: manishpharma@ yahoo.co.in

\section{Received April 23, 2012; Accepted May 23, 2012; Published May 25, 2012}

Citation: Patel Manish P, Patel Jayvadan K, Patel Ravi R, Patel Kalpesh N (2012) Microencapsulation of Verapamil Hydrochloride: A Novel Approach for Gastric Retention Using Different Polymers. Med chem 2: 076-080. doi:10.4172/2161. 0444.1000118

Copyright: @ 2012 Patel Manish P, et al. This is an open-access article distributed under the terms of the Creative Commons Attribution License, which permits unrestricted use, distribution, and reproduction in any medium, provided the original author and source are credited. 


\section{Characterization of floating microspheres:}

I. Measurement of micromeritic properties [16]: The flow properties of prepared floating microspheres were investigated by measuring the bulk density, tapped density, Carr's index, Housner's Ratio and angle of repose. The bulk and tapped densities were measured in a $10 \mathrm{ml}$ graduated measuring cylinder. The sample contained in the measuring cylinder was tapped mechanically by means of constant velocity rotating cam. The initial bulk volume and final tapped volume were noted from which, their respective densities were calculated. Results shown in Table 2.

$\%$ Compressibility index $=(\mathrm{TD}-\mathrm{BD} / \mathrm{TD}) \times 100$

Housner's Ratio $=\mathrm{TD} / \mathrm{BD}$

where TD $=$ Tapped Density and BD = Bulk Density

II. Particle size analysis: The particle size was determined using an optical microscope under regular polarized light, and mean particle size was calculated by measuring 200-300 particles with the help of a calibrated oculometer.

III. Yield of microspheres: The prepared microspheres were collected and weighed. The measured weight was divided by the total amount of all non-volatile components which were used for the preparation of the microspheres.
$\%$ Yield $=($ Actual weight of product $/$ Total weight of excipient and drug) $x 100$

IV. DEE (Drug Entrapment Efficiency): Microspheres equivalent to $50 \mathrm{mg}$ of the drug were taken for evaluation. The amount of drug entrapped was estimated by crushing the microspheres and extracting with aliquots of $0.1 \mathrm{~N} \mathrm{HCL}$ repeatedly. The extract was transferred to a $100 \mathrm{ml}$ volumetric flask and the volume was made up using $0.1 \mathrm{~N}$ $\mathrm{HCl}$. The solution was filtered and the absorbance was measured after suitable dilution spectrophotometrically at $278 \mathrm{~nm}$ against appropriate blank. The amount of drug entrapped in the microspheres was calculated by the following formula:

DEE $=($ Amount of drug actually present $/$ Theoretical drug load expected) $\mathrm{x} 100$

V. Scanning electron microscopy: Scanning electron microscopy (SEM) studies were performed to confirm the hollow nature of the microspheres. SEM photographs were taken at required magnification and at room temperature. Before scanning, the microspheres were sputtered with gold to make the surface conductive.

VI. In vitro evaluation of floating ability [17,18]: In vitro floatability studies of floating microspheres were carried out using USP apparatus II. To assess the floating Properties, the microspheres were placed in $0.1 \mathrm{~N}$ hydrochloric acid $(500 \mathrm{ml})$ containing $1 \%$ Tween 80 surfactant to simulate gastric conditions. The use of $1 \%$ tween was to

\begin{tabular}{|c|c|c|c|c|}
\hline Sr. No. & Formulation code & Drug: Polymer Ratio & Organic solvent system [1:1] & Continuous Phase \\
\hline 1 & $\mathrm{M}_{41}$ & $1: 1$ & Ethyl acetate: acetone & $100 \mathrm{ml}$ 0.5\% Polyvinyl alcohol \\
\hline 2 & $\mathrm{M}_{2}$ & $1: 2$ & Ethyl acetate: acetone & $100 \mathrm{ml}$ 0.5\% Polyvinyl alcohol \\
\hline 3 & $\mathrm{M}_{3}$ & $1: 1$ & Ethyl acetate: acetone & $100 \mathrm{ml}$ liquid paraffin \\
\hline 4 & M15 & $1: 1$ & Dichloromethane: ethanol & $100 \mathrm{ml}$ 0.5\% Polyvinyl alcohol \\
\hline 5 & $\mathrm{M}_{15}$ & $1: 2$ & Dichloromethane: ethanol & $100 \mathrm{ml}$ 0.5\% Polyvinyl alcohol \\
\hline 6 & $\mathrm{M} 15_{3}$ & $1: 1$ & Dichloromethane: ethanol & $100 \mathrm{ml}$ liquid paraffin \\
\hline 7 & $\mathrm{M} 100_{1}$ & $1: 1$ & Ethyl acetate: acetone & $100 \mathrm{ml}$ 0.5\% Polyvinyl alcohol \\
\hline 8 & $\mathrm{M} 100_{2}$ & $1: 2$ & Ethyl acetate: acetone & $100 \mathrm{ml}$ 0.5\% Polyvinyl alcohol \\
\hline 9 & $\mathrm{M} 100_{3}$ & $1: 1$ & Dichloromethane: ethanol & $100 \mathrm{ml}$ liquid paraffin \\
\hline
\end{tabular}

NOTE: - Formulations $M 4_{1}, \mathrm{M}_{2}$ and $\mathrm{M}_{3}$ containing MethocelK4M.

- Formulations $\mathrm{M15}_{1}, \mathrm{M15}_{2}$ and $\mathrm{M15}_{3}$ containing MethocelK15M.

- Formulations $\mathrm{M100}_{1}, \mathrm{M10O}_{2}$ and $\mathrm{M}_{100_{3}}$ containing MethocelK100M.

Table 1: Composition of formulations of floating microspheres.

\begin{tabular}{|c|c|c|c|c|}
\hline \multirow[b]{2}{*}{ Formulation code } & \multirow[b]{2}{*}{ Mean Particle Size $(\mu \mathrm{m}) \pm$ SD } & \multicolumn{3}{|c|}{ Flow Properties } \\
\hline & & $\%$ Compressibility \pm SD & Housner's Ratio \pm SD & Angle of Repose \pm SD \\
\hline $\mathrm{M}_{1}$ & 344.703 .81 & $13.86 \pm 0.26$ & $1.17 \pm 0.041$ & $25.42 \pm 0.67$ \\
\hline $\mathrm{M}_{2}$ & 360.753 .30 & $14.30 \pm 0.62$ & $1.19 \pm 0.007$ & $24.42 \pm 0.03$ \\
\hline $\mathrm{M}_{3}$ & 382.503 .09 & $16.43 \pm 0.23$ & $1.24 \pm 0.017$ & $23.89 \pm 0.55$ \\
\hline M15 & 252.454 .63 & $16.25 \pm 1.59$ & $1.24 \pm 0.028$ & $22.83 \pm 0.31$ \\
\hline $\mathrm{M} 15_{2}$ & 253.802 .27 & $15.86 \pm 2.92$ & $1.21 \pm 0.028$ & $22.63 \pm 0.60$ \\
\hline${\mathrm{M} 15_{3}}$ & 279.001 .27 & $17.78 \pm 0.56$ & $1.26 \pm 0.07$ & $29.88 \pm 0.07$ \\
\hline $\mathrm{M} 100_{1}$ & 418.958 .81 & $17.92 \pm 1.42$ & $1.26 \pm 0.016$ & $29.46 \pm 0.58$ \\
\hline $\mathrm{M} 100_{2}$ & 463.643 .68 & $19.36 \pm 2.10$ & $1.27 \pm 0.017$ & $30.23 \pm 0.28$ \\
\hline $\mathrm{M} 100_{3}$ & 411.614 .86 & $21.55 \pm 1.88$ & $1.29 \pm 0.041$ & $30.48 \pm 0.68$ \\
\hline Pure Drug & -- & $23.78 \pm 0.11$ & $1.29 \pm 0.007$ & $30.23 \pm 0.21$ \\
\hline
\end{tabular}

*Each observation is the mean \pm S.D. of three determinations

Table 2: Micromeritic properties of floating microspheres. 
account for the wetting effect of the natural surface active agents such as phospholipids in the GIT. A paddle rotating at $100 \mathrm{rpm}$ agitated the medium. Each fraction of microspheres floating on the surface and those settled down were collected at a pre-determine time point. The collected samples were weighed after drying.

\section{The buoyancy was calculated as}

$\%$ Floating microspheres $=\mathrm{QF} /(\mathrm{QF}+\mathrm{QS}) \times 100$

where QF and QS are weights of the floating and the settled microspheres respectively. Data of in vitro characteristics of floating microspheres are given in Table 3.

VII. In vitro Drug release studies: The drug release studies were carried out using six basket dissolution apparatus USP type II. The microspheres were placed in a non reacting mesh that had a smaller mesh size than the microspheres. The mesh was tied with a nylon thread to avoid the escape of any microspheres. The dissolution medium used was $900 \mathrm{ml}$ of $0.1 \mathrm{~N}$ hydrochloric acid at $37^{\circ} \mathrm{C}$. At specific time intervals, $5 \mathrm{ml}$ aliquots were withdrawn and analyzed by UV spectrophotometer at the respective $\lambda \max$ value $278 \mathrm{~nm}$ after suitable dilution against suitable blank. The withdrawn volume was replaced with an equal volume of fresh $0.1 \mathrm{~N}$ hydrochloric acid. Release profile shown in Figure 1.

VIII. Stability studies: With the recent trend towards globalization of manufacturing operation, it is imperative that the final product be sufficiently rugged for marketing world wide under various climatic conditions including tropical, sub tropical and temperate. Stability studies were carried out as per ICH guidelines. The floating microspheres were placed in a screw capped glass containers and stored at room temperature, $\left(25 \pm 2^{\circ} \mathrm{C}\right)$, oven temperatures $\left(40^{\circ} \mathrm{C}, 50^{\circ} \mathrm{C}\right.$, $\left.60^{\circ} \mathrm{C}\right)$, Humidity chamber $\left(37^{\circ} \mathrm{C} \pm 70 \% \mathrm{RH}\right)$, UV light, Deep freezer, and in Refrigerator $\left(2^{\circ}-8^{\circ} \mathrm{C}\right)$ for a period of 90 days. The samples were assayed for drug content at regular intervals of two weeks. The graph of percent drug content versus time (in days) was plotted. Data is given in Table 4. The graphical representation of stability studies of prepared floating microspheres at room temperature; Humidity chamber $\left(37^{\circ} \mathrm{C}\right.$ $\pm 70 \% \mathrm{RH})$ and Refrigerator $\left(2^{\circ}-8^{\circ} \mathrm{C}\right)$ are shown in Figure 2, 3 and 4.

\section{Results and Discussion}

Several preformulation trials were undertaken for various proportions of drug and polymer by variation of the ethyl acetateacetone ratio and dichloromethane-ethanol ratio. Methocel K4M, Methocel K15M and Methocel K100M were selected as matrixing agent considering its widespread applicability and excellent gelling

\begin{tabular}{|c|c|c|c|}
\hline $\begin{array}{c}\text { Formulation } \\
\text { code }\end{array}$ & \% Yield \pm SD & \% Drug Entrapped & $\begin{array}{c}\% \text { Buoyancy at 12 } \\
\text { h } \pm \text { SD }\end{array}$ \\
\hline $\mathrm{M} 4_{1}$ & 97.40 & $83.8 \%$ & $72.2 \pm 2.687$ \\
\hline $\mathrm{M}_{2}$ & 84.85 & $84.7 \%$ & $73.8 \pm 3.253$ \\
\hline $\mathrm{M}_{3}$ & 87.16 & $82.6 \%$ & $68.6 \pm 2.121$ \\
\hline $\mathrm{M} 15_{1}$ & 77.14 & $82.9 \%$ & $62.7 \pm 0.849$ \\
\hline $\mathrm{M} 15_{2}$ & 75.15 & $81.3 \%$ & $61.8 \pm 1.273$ \\
\hline $\mathrm{M} 15_{3}$ & 73.59 & $80.6 \%$ & $63.6 \pm 0.636$ \\
\hline $\mathrm{M} 100_{1}$ & 44.93 & $75.6 \%$ & $47.0 \pm 1.344$ \\
\hline $\mathrm{M} 100_{2}$ & 55.6 & $77.8 \%$ & $50.6 \pm 0.849$ \\
\hline $\mathrm{M} 100_{3}$ & 68.0 & $72.9 \%$ & $53.9 \pm 1.273$ \\
\hline
\end{tabular}

*Each observation is the mean \pm S.D. of three determinations

Table 3: Characteristics of verapamil hcl floating microspheres.

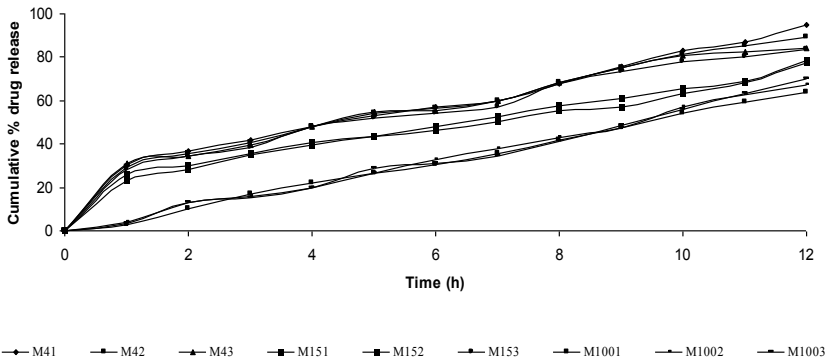

Figure 1: Release rate profile of formulated batches.
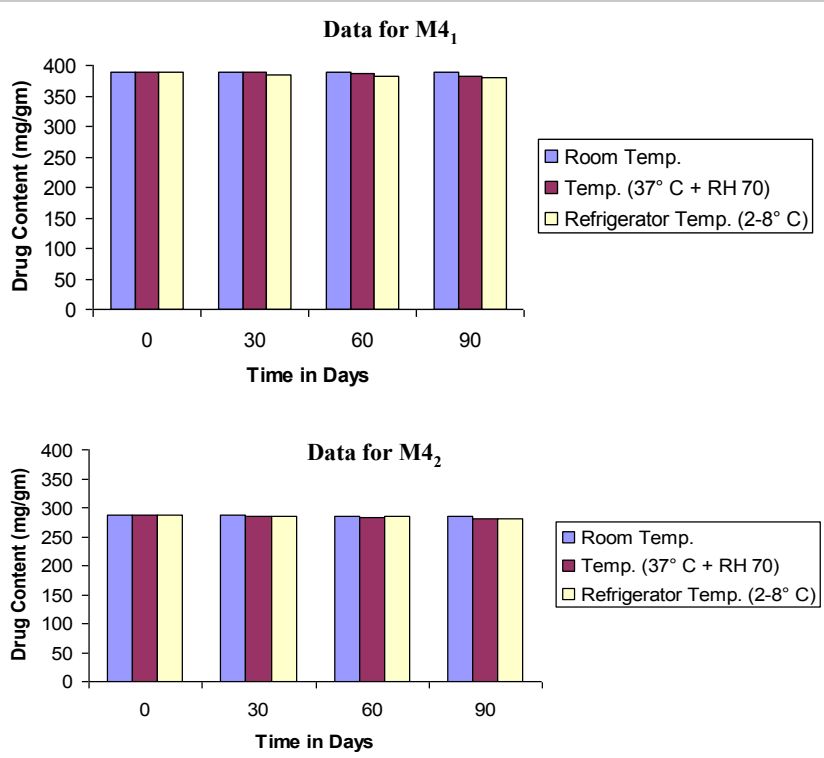

$\square$ Room Temp.

$\square$ Temp. $\left(37^{\circ} \mathrm{C}+\mathrm{RH} 70\right)$

$\square$ Refrigerator Temp. $\left(2-8^{\circ} \mathrm{C}\right)$

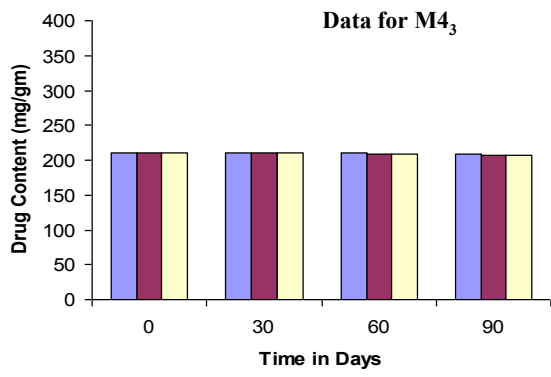

$\square$ Room Temp.

$\square$ Temp. $\left(37^{\circ} \mathrm{C}+\mathrm{RH} 70\right)$

$\square$ Refrigerator Temp. $\left(2-8^{\circ} \mathrm{C}\right)$

Figure 2: Graphical representation of stability studies of prepared floating microspheres (Formulation Code $\mathrm{M} 4_{1}, \mathrm{M} 4_{2}, \mathrm{M} 4_{3}$ ).

activity in sustain release formulations and also having the $\mathrm{pH}$ independent and reproducible drug release profile. It was found that Methocel K4M microspheres show desirable high drug content, yield, floatation and adequate release characteristics and hence was suitable for development of a controlled release system. No drug polymer incompatibility was noted in their FTIR spectra (Data are not shown). The surface morphology and internal texture of floating microspheres were determined by scanning electron microscopy (SEM). Presence of pores were detected on the microspheres surface which increased in number and size after dissolution, it shows that the drug leach out through these channels. The prepared microspheres were evaluated for the micromeritic properties. The average of three readings was taken. The mean particle size, flow properties and standard deviation were 
calculated. The low standard deviation of the measured mean particle size, \% Compressibility, Housner's Ratio and Angle of Repose of all the 9 formulations ensures the uniformity of the microspheres prepared by emulsion solvent evaporation method. The mean particle size was found to be in the range of $252.45 \pm 4.63 \mu \mathrm{m}$ to $463.64 \pm 3.68 \mu \mathrm{m}$. The variation in mean particle size could be due to variation in drugpolymer ratio. The $\%$ Compressibility of all the microspheres was found to be in the range of $13.86 \pm 0.26$ to $21.55 \pm 1.88$. The Housner's Ratio of all the microspheres was found to be in the range of 1.170 .041 to 1.29 \pm 0.041 . The Angle of Repose of all the microspheres was found to be in the range of $22.63 \pm 0.60$ to $30.48 \pm 0.68$. For the all formulations, $\%$ drug entrapped was found to vary $72.9 \%$ to $84.7 \%$ and it shows that the drug entrapment is higher in microspheres containing Methocel $\mathrm{K} 4 \mathrm{M}$ and lower in microspheres containing Methocel K100M. For the all formulations, \% yield was found to vary $44.93 \%$ to $97.40 \%$ and it shows that the yield is higher in microspheres containing Methocel $\mathrm{K} 4 \mathrm{M}$ and lower in microspheres containing Methocel K100M. All formulations floated for more than 8 hours on the simulated gastric fluid USP. But more than 60\% microspheres of Methocel K4M and Methocel $\mathrm{K} 15 \mathrm{M}$ were floated for 12 hours whether microspheres containing Methocel K100M did not show buoyancy up to 12 hours. In the present study, in vitro release studies of the floating microspheres were carried out in $0.1 \mathrm{~N}$ hydrochloric acid at $37^{\circ} \mathrm{C}$ for a maximum period of 12 hours. At different time intervals, samples were withdrawn and cumulative \% drug release was calculated. The percentage drug release of all the formulations is presented in Figure 1. Out of 9 formulations tried, the formulation M4 containing Methocel K4M
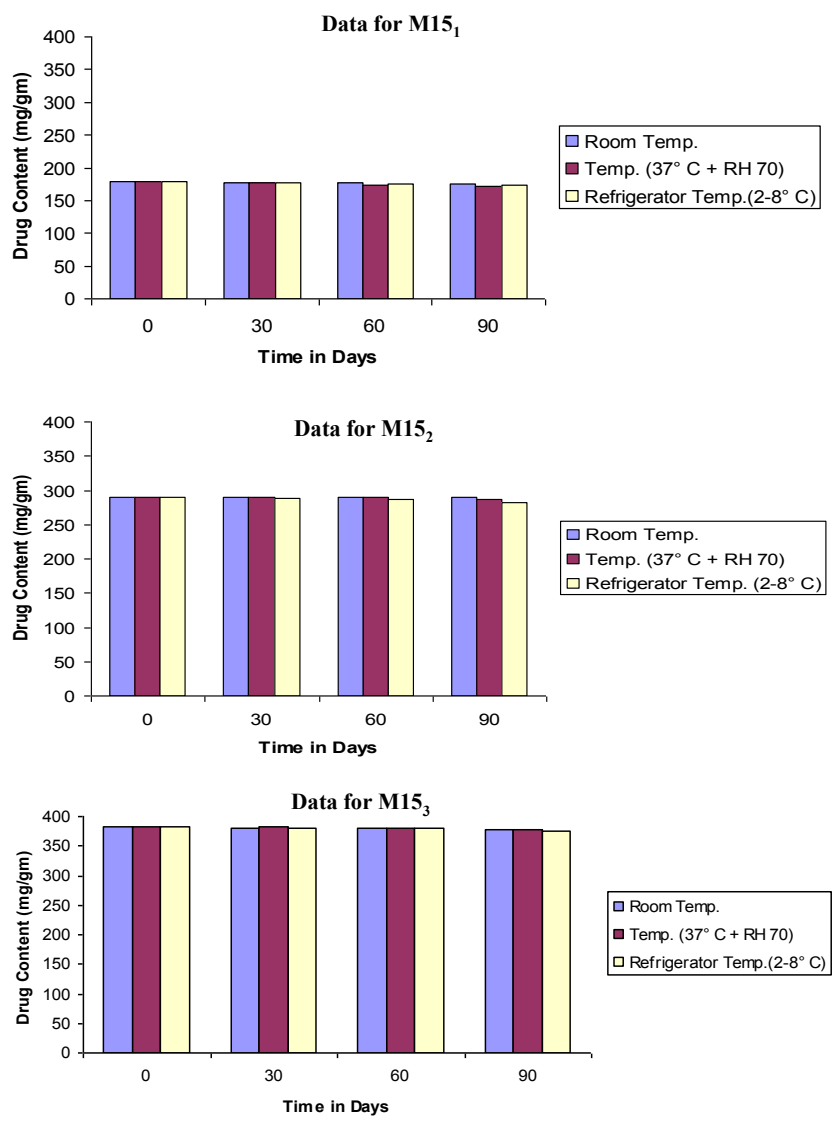

Figure 3: Graphical representation of stability studies of prepared floating microspheres (Formulation Code $\mathrm{M} 15_{1}, \mathrm{M}_{1} 5_{2}, \mathrm{M} 15_{3}$ ).
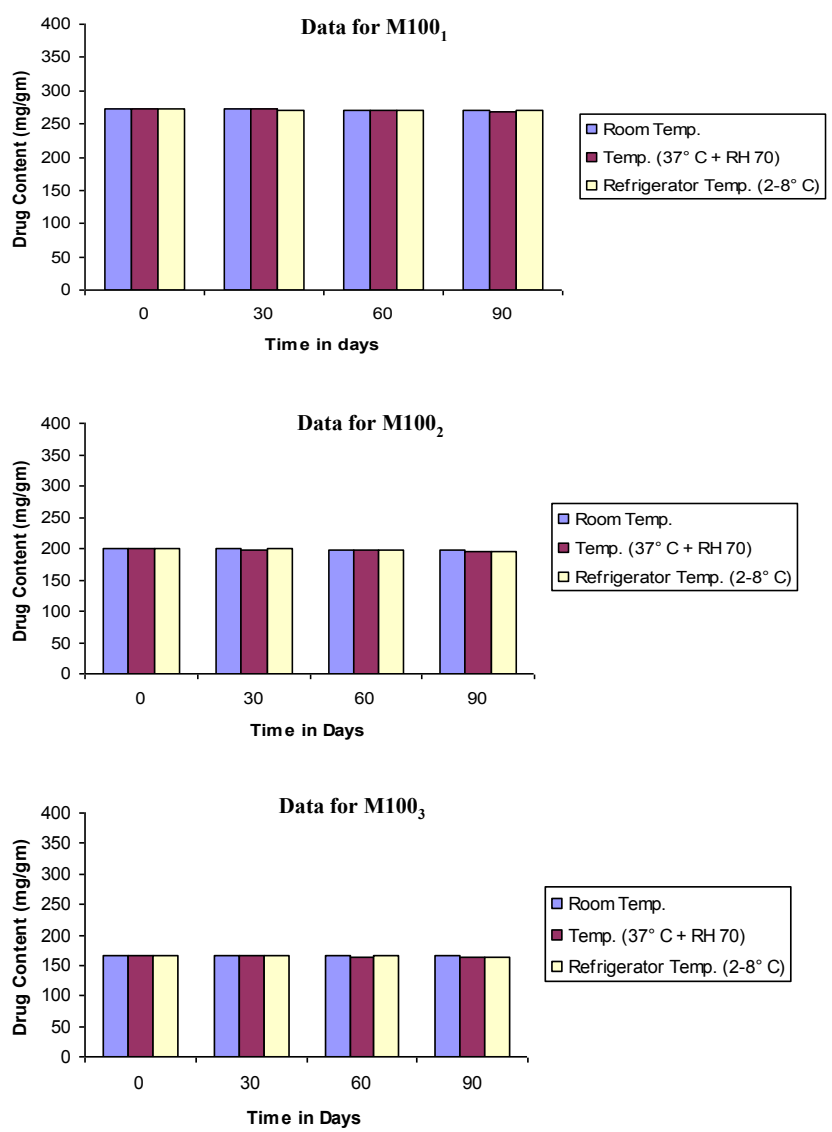

Figure 4: Graphical representation of stability studies of prepared floating microspheres (Formulation Code $\mathrm{M} 100_{1}, \mathrm{M} 100_{2}, \mathrm{M}_{100}$ ).

was found to be satisfactory; since it showed prolonged and complete release with $94.75 \%$ at end of $12 \mathrm{~h}$. It was reasoned that the rate of swelling of particles with high viscosity grade was slow compared with low viscosity HPMC. The in vitro release data of all formulations were also subjected to model fitting analysis to know the mechanism of drug release from the formulations by treating the data according to zero order, first order, higuchi and Peppas equation. The results are shown in Table 5. It can be interpreted from the result that the release of drug from the microspheres followed zero order kinetics. Further, the higuchi plot revealed that the drug release from the microspheres obeyed diffusion mechanism. It can be concluded that the formulation of microspheres (M4 $)$ containing Verapamil hydrochloride and MethocelK4M (1:1) seems to be promising and further in vivo study must be carried out to check the efficacy of preparations. In vivo floating ability of microspheres was studied; X-ray photograph of dog stomach with barium sulphate containing floating microspheres is shown in Figure 2. Stability studies for all formulations were performed for three months, at room temperature $\left(25^{\circ} \pm 2^{\circ} \mathrm{C}\right)$, at refrigeration temperature $\left(2^{\circ}\right.$ to $\left.8^{\circ} \mathrm{C}\right)$, at $37^{\circ} \mathrm{C} / \mathrm{RH} 70$. The floating microspheres were stored at various above mentioned temperatures .The prepared microspheres were subjected for drug content analysis after every one month interval. The data are shown in Table 4. Histogram was plotted between drug content ( $\mathrm{mg} / \mathrm{gm})$ and time (In days), stability profile of different formulations at various temperatures is shown in Figure 3, 4 and 5. The data depicts that the floating microspheres stored at room temperature, refrigeration temperature, were found to be comparatively stable and at $37^{\circ} \mathrm{C} / \mathrm{RH} 70$ there was less than $5 \%$ degradation at the end of three months. 
Citation: Patel Manish P, Patel Jayvadan K, Patel Ravi R, Patel Kalpesh N (2012) Microencapsulation of Verapamil Hydrochloride: A Novel Approach for Gastric Retention Using Different Polymers. Med chem 2: 076-080. doi:10.4172/2161-0444.1000118

\begin{tabular}{|c|c|c|c|c|c|c|c|c|c|c|c|c|}
\hline \multirow{4}{*}{ Formulation code } & \multicolumn{12}{|c|}{ Drug content (mg/gm) } \\
\hline & \multicolumn{4}{|c|}{ Room Temperature $\left(25 \pm 2^{\circ} \mathrm{C}\right)$} & \multicolumn{4}{|c|}{ Temperature $\left(37^{\circ} \mathrm{C}+\mathrm{RH} 70\right)$} & \multicolumn{4}{|c|}{ Refrigerator Temperature $\left(2-8^{\circ} \mathrm{C}\right)$} \\
\hline & \multicolumn{4}{|c|}{ Time in days } & \multicolumn{4}{|c|}{ Time in days } & \multicolumn{4}{|c|}{ Time in days } \\
\hline & 0 & 30 & 60 & 90 & 0 & 30 & 60 & 90 & 0 & 30 & 60 & 90 \\
\hline $\mathrm{M}_{4} 1$ & 390.0 & 389.4 & 388.4 & 388.3 & 390.0 & 389.3 & 386.4 & 381.3 & 390.0 & 385.1 & 383.2 & 378.9 \\
\hline $\mathrm{M}_{2}$ & 287.0 & 286.8 & 285.6 & 285.3 & 287.0 & 285.3 & 283.1 & 281.4 & 287.0 & 285.2 & 284.3 & 281.8 \\
\hline $\mathrm{M}_{3}$ & 211.0 & 210.8 & 209.9 & 209.3 & 211.0 & 210.2 & 208.1 & 206.3 & 211.0 & 210.3 & 208.9 & 206.8 \\
\hline $\mathrm{M} 15_{1}$ & 178.4 & 177.4 & 177.0 & 176.1 & 178.4 & 176.3 & 173.7 & 171.8 & 178.4 & 177.4 & 175.2 & 173.9 \\
\hline${\mathrm{M} 15_{2}}_{2}$ & 290.6 & 290.2 & 289.9 & 289.8 & 290.6 & 289.8 & 289.7 & 286.7 & 290.6 & 288.3 & 286.5 & 282.7 \\
\hline $\mathrm{M} 15_{3}$ & 382.0 & 381.2 & 380.6 & 379 & 382.0 & 381.6 & 380.5 & 377.9 & 382.0 & 380.9 & 379.1 & 375.7 \\
\hline $\mathrm{M} 100_{1}$ & 272.6 & 271.9 & 271.3 & 270.6 & 272.6 & 272.3 & 269.7 & 269.1 & 272.6 & 271.1 & 270.4 & 269.8 \\
\hline $\mathrm{M} 100_{2}$ & 199.2 & 199.3 & 198.6 & 197 & 199.2 & 198.3 & 197.4 & 194.8 & 199.2 & 198.9 & 197.2 & 194.3 \\
\hline $\mathrm{M} 100_{3}$ & 166.4 & 165.6 & 165.2 & 164.7 & 166.4 & 166.2 & 164.3 & 163.6 & 166.4 & 165.9 & 164.8 & 163.6 \\
\hline
\end{tabular}

Table 4: Stability studies of floating microspheres stored at different temperature for 3 months.

\begin{tabular}{|c|c|c|c|c|c|c|c|c|}
\hline \multirow[b]{2}{*}{ Formulation code } & \multicolumn{2}{|c|}{ Zero order } & \multicolumn{2}{|c|}{ First order } & \multicolumn{2}{|c|}{ Higuchi's kinetics } & \multicolumn{2}{|c|}{$\begin{array}{l}\text { Peppas double log } \\
\text { plots }\end{array}$} \\
\hline & $\begin{array}{l}\text { Rate } \\
\text { Constant (K) } \\
\text { mg. } \text { min }^{-1}\end{array}$ & $\begin{array}{c}\text { Regression } \\
\text { coefficient } \\
\left(\mathbf{R}^{2}\right)\end{array}$ & $\begin{array}{c}\text { Rate } \\
\text { Constant } \\
\text { (K) } \mathrm{mg} \cdot \mathrm{min}^{-1}\end{array}$ & $\begin{array}{c}\text { Regression } \\
\text { Coefficient } \\
\qquad\left(R^{2}\right)\end{array}$ & $\begin{array}{l}\text { Rate constant } \\
\text { (K) } \mathrm{mg} \mathrm{min}^{-1}\end{array}$ & $\begin{array}{l}\text { Regression } \\
\text { coefficient } \\
\left(\mathbf{R}^{2}\right)\end{array}$ & Slope(n) & $\begin{array}{c}\text { Regression } \\
\text { coefficient } \\
\left(R^{2}\right)\end{array}$ \\
\hline M4 & 6.512 & 0.9438 & -0.197 & 0.8541 & 25.582 & 0.9753 & 0.4614 & 0.9543 \\
\hline $\mathrm{M}_{2}$ & 6.3072 & 0.9401 & -0.164 & 0.9399 & 24.949 & 0.9852 & 0.4673 & 0.9695 \\
\hline $\mathrm{M4}_{3}$ & 6.051 & 0.9257 & -0.143 & 0.9647 & 24.109 & 0.9842 & 0.4475 & 0.9542 \\
\hline M15 & 5.3592 & 0.9468 & -0.102 & 0.9518 & 21.13 & 0.9858 & 0.4896 & 0.9790 \\
\hline $\mathrm{M}_{15}$ & 5.0046 & 0.9240 & -0.092 & 0.9223 & 19.848 & 0.9734 & 0.4276 & 0.9527 \\
\hline $\mathrm{M}_{15}$ & 5.9786 & 0.9310 & -0.136 & 0.9691 & 23.779 & 0.9863 & 0.4644 & 0.9693 \\
\hline M100 & 5.4035 & 0.9977 & -0.087 & 0.9779 & 19.995 & 0.915 & 1.1545 & 0.982 \\
\hline $\mathrm{M} 10 \mathrm{O}_{2}$ & 5.6227 & 0.9962 & -0.094 & 0.9657 & 20.734 & 0.9073 & 1.0592 & 0.9873 \\
\hline $\mathrm{M} 10 \mathrm{O}_{3}$ & 5.7235 & 0.9899 & -0.098 & 0.9416 & 20.988 & 0.8916 & 1.1317 & 0.9741 \\
\hline
\end{tabular}

Table 5: Kinetic data of drug release from various formulations.

\section{References}

1. Colombo P, Bettini R, Santi P, Peppas NA (2000) Swellable matrices for controlled drug delivery: gel layer behavior, mechanisms and optimal performance. Pharm Sci Technolo Today 3: 198-204.

2. Baumgartner S, Kristl J, Vrecer F, Vodopivec P, Zorko B (2000) Optimization of floating matrix tablets and evaluation of their gastric residence time. Int $J$ pharm 195: 125-135.

3. Jain SK, Chourasia MK, Jain AK, Jain RK, Shrivastava AK (2004) Development and Characterization of mucoadhesive microspheres bearing salbutamol for nasal Delivery. Drug Deliv 11: 113-122.

4. Cuña M, Alonso MJ, Torres D (2001) Preparation and in vivo evaluation of mucoadhesive microparticles containing amoxicillin-resin complexes for drug delivery to the gastric mucosa. Eur J Pharm Biopharm 51: 199-205.

5. Santus G, Lazzarini C, Bottoni G, Sandefer EP, Page RC, et al. (1997) An in vitro-in vivo investigation of oral bioadhesive controlled release furosemide formulations. Eur J Pharm Biopharm 44: 39-52.

6. Deshpande AA, Rhodes CT, Shah NH, Malick AW (1996) Controlled release drug delivery systems for prolonged gastric residence: An overview. Drug Development and Industrial Pharmacy 22: 531-539.

7. Deshpande AA, Shah NH, Rhodes CT, Malick W (1997) Development of a novel controlled release system for gastric retention. Pharm Res 14: 815-819.

8. Menon A, Ritschel WA, Sakr A (1994) Development and evaluation of a monolithic floating dosage form of furosemide. J Pharm Sci. 83: 239-245.
9. Whitehead L, Fell JT, Collett JH, Sharma HL, Smith A (1998) Floating dosage forms: An in vivo study demonstrating prolonged gastric retention. J Control Release 55: 3-12.

10. Singh BN, Kim KH (2000) Floating drug delivery systems: An approach to ora controlled drug delivery via gastric retention. J Control Release 63: 235-259.

11. Chawla G, Gupta P, Koradia V, Bansal AK (2003) A means to address regional variability in intestinal drug absorption. Pharm Tech 27: 50-68.

12. Kirsten R, Nelson K, Kirsten D, Heintz B (1998) Clinical Pharmacokinetics of Vasodilators: Part II. Clin Pharmacokinet 35: 9-36.

13. Sasaki S, Tateishi T, Ebihara A (1993) The effect of age and gender on the stereoselective pharmacokinetics of verapamil. Clin Pharmacol Ther 54: 278 285.

14. Soppimath KS, Kulkarni AR, Aminabhavi TM (2001) Development of Hollow microspheres as Floating Controlled Release Systems for Cardiovascular Drugs. Drug Dev Ind Pharm 27: 507-515.

15. Kale R, Rao BS, Sharma S, Ramanmurthy KV (2001) Preparation and Evaluation of Floatable Drug Delivery System of Ketorolac Tromethamine. Int J Pharm Excp 64-65.

16. Martin A (1983) Physical Pharmacy. Lea Febiger, Philadelphia, USA.

17. Iannuccelli V, Coppi G, Bernabei MT, Cameroni R (1998) Air compartment multiple-unit system for prolonged gastric residence. Part I. Formulation study. Int J Pharm. 174: 47-54.

18. Lee JH, Park TG, Choi HK (1999) Development of oral drug delivery system using floating microspheres. J Microencapsul 16: 715-729. 